\title{
Mapping of the Strategic Positioning and Sequencing through the Integrated Value Creation Model: The Wholesale Spare Parts Distribution in the Italian Automotive Independent After Market in the 2008-2011 Period
}

\author{
Silvano Guelfi ${ }^{1}$ \\ ${ }^{1}$ Strategy \& Finance, Planning \& Control, Strategic Marketing, Department of Management and Production \\ Engineering, Politecnico di Torino, Torino, Italy \\ Correspondence: Guelfi Silvano, Professor of Strategy \& Finance, Planning \& Control, Strategic Marketing, Director \\ of the research group Competitive Risk and Enterprise Value, Politecnico di Torino, Turin, 10129, Italy. Tel: \\ 39-11-090-7214.E-mail: silvano.guelfi@polito.it
}

Received: June 20, 2013

doi:10.5430/ijba.v4n4p68
Accepted: July 9, 2013

Online Published: July 13, 2013

\begin{abstract}
From always, strategy and value creation are linked by a precise cause and effect relationship. In particular, companies challenge each other to identify and realize the most suitable strategies to create competitiveness and economic value and the latter is recognized, by the scientific community as well as from the professional world, as the true measure of the quality of the company strategies. In this direction, the present essay investigates the possibility to evaluate the quality of the strategic process of the company through its mapping of the strategic positioning and sequencing in turn based on the metric of the current value creation, i.e. the realized results in the present, and the strategic value creation, i.e. the sown results for the future. The possible combinations of the mentioned above current and strategic value creation highlight four main types of business strategy: the long vision strategy opposed to the no future strategy and the harvesting/breath strategy opposed to the changing strategy. In this direction, the best company is the one who knows how to collect results in the present (i.e. a positive current value creation) and at the same time it is able to sow/invest for the future (i.e. a positive strategic value creation). At the end the above relationship between strategy and value creation is synthetically applied to the Wholesale Spare Parts Distributors operating in the Italian Automotive Independent After Market for the period 2008-2011: the sample, composed of 168 limited companies, represents more than $98 \%$ of the value of total production (approximately 2,0 billion euro).
\end{abstract}

Keywords: value creation, strategic positioning, strategic sequencing, goodwill, economic profit

\section{Introduction}

The academic and financial community has always considered the quality of the competitive strategy as the starting point for the consistency and continuity of the economic wealth creation. In full agreement with this cause-effect relationship, the present paper investigates the possibility of identifying the nature and quality of the competitive strategy through the ex-post analysis of the consistency and continuity of the economic wealth creation.

In particular, the integrated value creation (from now on indicated with the acronym IVC) model used for measuring the creation of economic wealth is based on the economic methodology of the Value Based Management (Marshall, 1890; Modigliani \& Miller, 1958, 1963; Rappaport, 1986; Bennet Stewart III, 1991; Prahalad, 1994; Damodaran, 2004). This IVC model, in summary, includes in a single measure two different (by nature, tangibility and time horizon) but "sine qua non" components: the economic profit realized in each period (comparable, for example, to the dividends earned by the shareholder) and the economic result connected to the changing expectations of future performance (in turn embedded in the changing value of the capital invested and comparable, for example, to the capital gain/loss realized by the shareholder). Both results are a direct expression of the enterprise quality management and they arise from the managerial ability to operate, at the same time, optimizing the present and building the future. It's the eternal challenge between "harvest" and "sowing", the short-term view and the long-term 
vision, the "carpe diem, quam minimum credula postero" (seize the day, trusting as little as possible in the next (day)[future]) of Horatio and "nulla dies sine linea" (no day without a line) of Pliny the Elder.

The next step consists in mapping the possible combinations between these two components of value creation and it helps to qualify the strategy pursued by the company with a double level of evaluation: the first judgment is related to the strategic positioning in each year of the period analysis (the so-called strategic positioning) and the second evaluation refers to the succession over time of different strategic positions (the so-called strategic sequencing). In particular, it's this second assessment which allows to qualify the strategic process that by its nature, on the one hand, requires a multi-year evaluation horizon and, on the other side, it is expressed in relation to the coherence between the strategic position achieved in a given year and the one recorded in the following periods.

As will be described in the following third paragraph, the mapping of the strategic positioning and sequencing will highlight respectively, through the integrated value creation model, four possible strategic positioning and eleven different strategic sequences and related company's profiles.

The integrated value creation model and the strategic positioning/sequencing tool, once outlined in their main theoretical aspects, are then used to analyze the strategic dynamics of a real economic sector, so that the reader can better appreciate meanings, scopes and application problems.

\section{The Value Creation Framework}

In general terms, the concept of value creation is very simple and well known (please refer to the Shareholder Value Approach or Value Based Management) to the science of economics: for the holder of a particular capital, the economic value is created, in a specific time period, if the total remuneration of which he benefits is greater than that capital would have earned if employed alternately at similar risk conditions.

The above definition highlights six main guidelines:

1) the value creation is a magnitude-flow and it belongs to the family of the economic variables whose measure can be found only with reference to a specific time period (e.g., one year);

2) the value creation is a comprehensive measure of all the economic benefits enjoyed, in a given period, by the holder of the capital invested. In particular, the Integrated Value Creation originates from the sum of two components:

2.1)the current result, hereinafter referred to as Current Value Creation CVC, which is the result actually achieved through the operational management of the year: it's a "partial" outcome measure because, on the one hand, it's entirely dependent on events that have characterized the business in a short term outlook and, on the other side, it doesn't give evidence of the intensity and quality of efforts through which the company is orienting its own future results;

2.2) the strategic outcome, later identified with the term Strategic Value Creation SVC, which represents the profit generated by the strategic governance of the business in a medium-long term perspective: this outcome too is a "partial" measure as, on the one hand, it's entirely attributable to the planned/expected performance for the future (and for that reason based on sizes inevitably volatile and subjective) and, on the other side, unable of giving evidence of the result actually achieved in the period;

3) the value creation may arise from two possible sources: the first (operating source) is related to the net operating results (the so-called Nopat, net operating profit after taxes, or Ebiat, earnings before interests after taxes) generated by the core business assets (the so-called Nci, net capital invested) of the company and the second (financial source) is determined by the tax deductibility (unlike dividends) of interest expenses paid on financial debts (Modigliani \& Miller, 1963);

4) the value creation can be appreciated only by explicitly considering the opportunity cost of capital, e.g., the yield that the capital is expected to generate to compensate for the risk to the investor (the so-called cost of capital, hurdle rate, expected return, minimum acceptable rate of return, discount rate, etc.): in this sense, the value creation is a true economic measure because it incorporates the remuneration of all the input factors including the risk borne by the investors. For example, the holder of an equity security measures the total actual performance of the investment considering an appropriate return on risk directly linked to the volatility of the share price and related dividends;

5) the value creation implies that all the ingredients necessary for its measurement are mutually consistent (or, in other words, homogeneous) and, in particular, that are expressed in the current economic value. Thus, if the result for the year attributable to a particular share is by nature already expressed in current values (as accrued 
during the year) also the capital invested must be expressed at current value: it means that the beginning amount of invested capital change its value in relation to its distinctive attitude to generate, over time, superior (inferior) results compared to the normal return obtained in the business: this positive (negative) difference is the so-called extra profit (loss), on which it is based, as we shall see in the next third paragraph, the well-known economic size of Good(Bad)will. The algebraic sum of these two addendum, the beginning capital amount and its greater (lower) value generated from the expected extra profits (losses), determines the so-called economic value of the capital invested. For example, an holder of an equity security measure his performance through the so-called Total Shareholder Value, that is the ratio between dividends added to the stock value change and the latter expressed at current value (not at the purchasing historic value) at the beginning of the period;

6) the value creation is a concept referable to any person holding a capital of any kind: from the owner of a particular economic good (property, patent, copyright, etc.) to the worker (manager, professional, artisan, etc.) who has his own professional capital up to the lenders of the company (shareholders and third-parties lenders of debt).

As concern the objective of this article and the coherent configuration of value creation analyzed, the following assumptions have been made:

1) the mapping of the strategic positioning/sequencing relates exclusively to the identification and evaluation of competitive strategies focused on the company core business: this choice implies to consider just the operating value creation, to exclude the financial value creation (and the related trade-off between the tax shield value and the financial distress value, Myers, 1974) and so to consider the company as an all-equity financed entity;

2) the corporate taxes are the only ones to be considered while the personal (investors/shareholders) taxes (Miller, 1977) are excluded from any assessment;

3 ) in relation to the appropriate economic and financial corrections to be made, with the aim of providing maximum significance to the subsequent measures of value creation, net operating profit after taxes and net capital invested, please refer to the extensive literature available on the subject (Bennet Stewart III, 1991; Donna, 1999).

\subsection{Expectations of Future Performance and Good(Bad)will Value}

The measurement of the integrated value creation, in the two current and strategic components, revolves around a fundamental concept of business economics: the well-known Goodwill (or Badwill) value. Of course, the theme of the quantitative determination of goodwill is largely covered by the academic and professional literature. But it should be noted, to avoid any misunderstanding, that here the Goodwill represents a peculiar object of investigation and quantification, as it is interpreted not as an entity to appreciate exceptionally, as typically happens in extraordinary transactions such as the purchase or sale of business, but as an entity to appreciate periodically in a systematic way, as an integral component of the performance measure IVC.

In summary, the Good(Bad)will value:

1) represents the difference between the amount (recorded at book value) of net invested capital (NCI) and its economic value $\left(\mathrm{NCI}_{\mathrm{V}}\right)$ or, as concern an all-equity company, the difference between the equity book value $(\mathrm{E})$ and its economic value $\left(\mathrm{E}_{\mathrm{V}}\right)$. In formula:

$$
G=E_{V}-E
$$

but also:

$$
E_{V}=E+G
$$

2) is driven by expectations regarding future performance which in turn affect the economic value of capital invested as much as they show:

2.1) a robust attitude to achieve excess returns (the so-called extra-profit), ie superior results to those normally obtainable in alternative investments of equal risk (the so-called opportunity cost);

2.2) a consistent ability to replicate over time these extra-profits.

In relation to the principle (widely shared by the studies of Business Administration) that these excess returns are achievable "only" through a competitive advantage position and "only" for the related duration, it follows that Goodwill (G) is by definition equal, under an equity side evaluation perspective and for an all-equity company, to the sum of the extra net incomes (Eni) expected during the competitive advantage period (well known in the literature with the acronym CAP, Mauboussin, 1997), appropriately discounted at the cost of equity (CoE, equal to the 
required return on the firm's assets for an all-equity company). As concern the CAP measure "Past research shows that there is a strong tendency for earnings to return toward an average level - again, after adjusting for inflation and a normal growth rate - after a sharp increase or decrease. This tendency to revert to the mean reflects the operation of competitive market forces that push most firms toward average levels of performance. Competitive forces make it hard to sustain abnormally good performance for long. At the same time, firms with abnormally poor performance are generally prodded by capital markets (if not internal board-level pressure) into improvements" (Opler et al., 1997).

Referring to other studies in which the theme is properly developed (Donna, 2003; Rappaport \& Maboussin, 2003), here we limit ourselves to highlight, among the many possible, a first more general formula and a second more analytical, and consistent with the object of this essay, formula. In particular, in symbols:

a. the first general formula shows how the Goodwill value is equal to the sum of the $i$-th expected (for a certain $n$ competitive advantage period) extra net incomes (ENI) discounted at the $i$-th cost of equity CoE (in other word Goodwill is equal to the net present value of future extra net incomes; as in the same way it's equal to the net present value of future discounted cash flows, Costantini, 2006):

$$
\underset{i=1}{G=\sum E n i_{i} /\left(1+C o E_{i}\right)^{n}}
$$

b. the second more analytical formula defines Goodwill as follows:

$$
G=E x\left[R x\left(1-t_{c}\right)-\operatorname{CoE}\right] x\left\{1-[(1+g) /(1+\operatorname{CoE})]^{n}\right\} /(C o E-g)
$$

where:

$\mathrm{E}=$
$\mathrm{R}=$
$\mathrm{t}_{\mathrm{c}}=$
$\mathrm{CoE}=$
$\mathrm{g}=$
$\mathrm{n}=$
shareholders' equity (i.e., capital financed by shareholders); normal expected rate of return, corresponding responding to the return on equity (before taxes) that on average the firm is supposed to be able to generate, given its competitive strength; rate of corporate taxation that affects the average income earned; cost of equity (net of tax) related to the riskiness of the company (Modigliani \& Miller, 1958); average annual growth rate expected during the CAP period; duration of competitive advantage (the so-called in the literature CAP, competitive advantage period), i.e. time horizon over which the capital invested is expected to make more of its cost (Besanko et al., 2000; Greenwald et al., 2001);

If we define the symbol $s$ the difference between the return, $\mathrm{R} \mathrm{x}\left(1-\mathrm{t}_{\mathrm{c}}\right)$, and the cost of equity, CoE, and the symbol $m$ the capital ratio of a limited annuity, $\left\{1-[(1+\mathrm{g}) /(1+\mathrm{CoE})]^{\mathrm{n}}\right\} /(\mathrm{CoE}-\mathrm{g})$, we obtain respectively the so-called spread value and a particular profit multiplier to arrive to $\mathrm{G}$ and we can simplify the formula:

$$
G=E \times s \times m
$$

To facilitate the understanding of the Integrated Value Creation Model and its interrelations with Goodwill, consider, for example, the following 2011-2012 Balance Sheet and Profit \& Loss (Table 1) and estimates of the Goodwill drivers (Table 2) related to the all-equity Alfa company.

Table 1. Balance sheet and profit \& loss: The all-equity Alfa company

\begin{tabular}{lrrr}
\hline Balance Sheet & Year 2011 & Year 2012 & $\Delta 2012 / 2011$ \\
\hline Net capital invested (Nci) & 9.000 & 9.450 & +450 \\
Equity (E) & 9.000 & 9.450 & +450 \\
\hline Profit \& Loss & Year 2011 & Year 2012 & \\
\hline Earnings before interests and taxes (Ebit) & 2.025 & \\
Interests & 0 & \\
Earnings before interests (Ebt) & 2.025 & \\
Corporate taxes $\left(\mathrm{t}_{\mathrm{c}}\right)$ & $(675)$ & \\
Net income (Ni) & 1.350 & \\
\hline
\end{tabular}


Table 2. Estimates of the goodwill and its drivers: The all-equity Alfa company

\begin{tabular}{lrrr}
\hline The Goodwill and its drivers & \multicolumn{1}{c}{ Year 2011} & Year 2012 & \multicolumn{1}{c}{$\Delta 2012 / 2011$} \\
\hline Goodwill (G) & 2.857 & 4.891 & +2.033 \\
Spread value (s) & $5,67 \%$ & $8,17 \%$ & $+1,50 \%$ \\
Profit multiplier (m) & 5,60 & 6,34 & $+0,74$ \\
Equity (E) & 9.000 & 9.450 & +450 \\
Normal expected rate of return (R) & $22,00 \%$ & $25,00 \%$ & $+3,00 \%$ \\
Expected rate of corporate taxation ( $\left.\mathrm{t}_{\mathrm{c}}\right)$ & $33,33 \%$ & $33,33 \%$ & $0,00 \%$ \\
Expected cost of equity (CoE) & $9,00 \%$ & $8,50 \%$ & $(0,50 \%)$ \\
Expected growth rate (g) & $4,00 \%$ & $3,75 \%$ & $(0,25 \%)$ \\
Expected duration of competitive advantage & 7,00 & 8,00 & $+1,00$ \\
(CAP) & & & \\
\hline
\end{tabular}

Using these assumptions, we obtain the following Goodwill values:

$$
\begin{gathered}
G_{2012}=9.450 \times(25,00 \% \times 0,67-8,50 \%) \times\left\{1-[(1+3,75 \%) /(1+8,50 \%)]^{8}\right\} /(8,50 \%-3,75 \%)= \\
9.450 \times 8,17 \% \times 6,34=4.891 \\
G_{2011}=9.000 \times(22,00 \% \times 0,67-9,00 \%) \times\left\{1-[(1+4,00 \%) /(1+9,00 \%)]^{7}\right\} /(9,00 \%-4,00 \%)= \\
9.000 \times 5,67 \% \times 5,60=2.857
\end{gathered}
$$

The goodwill improvement, $\Delta \mathrm{G}=\mathrm{G}_{2012}-\mathrm{G}_{2011}=4.891-2.857=+2.033$, is due to two positive effects: a better spread value, $+1,50 \%$, and a better profit multiplier, $+0,74$.

\subsection{Current Value Creation}

As mentioned earlier (see paragraph 2, point 4), the value creation can be appreciated only by explicitly considering the opportunity cost of capital, i.e. the benefit that the holder of the capital could obtain employing the latter in an alternative investment of comparable risk. In order to express the true current value creation there are two critical points:

1) the first refers to the determination of the above opportunity cost that for an all-equity company is equal to the minimum return expected/pretended by the shareholders as compensation for the waiting time and risk, the so-called cost of equity CoE. Finance theory and practice offers various models for estimating the firm's cost of equity among which the most known is the Capital Asset Pricing Model, or CAPM (Treynor, 1961; Sharpe, 1964; Lintner, 1966; Fama et al., 1997), which offers the following formula:

$$
\mathrm{CoE}=r_{f}+M P R \times \beta_{e}
$$

where:

$\mathrm{r}_{\mathrm{f}}=\quad$ risk-free rate is the rate of interest such as interest arising from government bonds;

$\mathrm{MPR}=$ market premium risk is the difference between the expected average market rate of return and the risk-free rate of return;

$\beta_{\mathrm{e}}=\quad$ firm's risk ratio is a function of both financial leverage (D / E) and asset risk $\left(\beta_{\mathrm{a}}\right)$ : the most common relationship between $\beta_{\mathrm{e}}$ and $\beta_{\mathrm{a}}$ is the following (referring to other studies in which the theme is properly developed): $\beta_{e}=\beta_{a} x\left[1+\left(1-t_{c}\right) \times(D / E)\right]$. For an all equity company $\mathrm{D} / \mathrm{E}$ is equal to zero, there is no financial risk due to leverage and consequently $\beta_{\mathrm{e}}=\beta_{\mathrm{a}}$;

2) the second critical point concerns (please see paragraph 2, point 5) the capital invested to be remunerated which must be expressed not so much as the amount of capital employed in the enterprise (the so called equity book value), but in terms of current economic value: continuing to assume the working hypothesis of an all-equity company that current economic value of capital is the so-called economic value of shareholders' equity. It is only with reference to this value that the investor can judge whether and to what extent the performance achieved in the period, expressed at the current value, has been satisfactory.

Absolved the two previous critical points, the operation to obtain the current value creation is very simple: it's sufficient to deduct from the net income the capital charge generated by the product between the cost of equity and the current economic value of equity. As concern this latter value is defined, to homogenise a flow-value as the net 
income and a status-flow as the equity, as an arithmetic average between beginning and final values. The CVC formula is the following:

$$
C V C=N i-\operatorname{CoE} x\left[\left(E_{V 1}+E_{V 0}\right) / 2\right]
$$

Continuing the example of the Alfa company and supposing an appropriate cost of equity of $8,00 \%$, it follows that the economic benefit, alias current value creation, achieved by the shareholder is equal to the net income minus a cost of equity of $8,00 \%$ of the average current economic value of equity:

$$
C V C=1.350-8,00 \% \times[(11.857+11.341) / 2]=237
$$

The CVC achieved is a measure of "performance" most comprehensive of net income, as it incorporates two additional dimensions: the amount, expressed at the current economic value, of the capital contributed by shareholders and, with the minimum rate of return expected from them, the degree of risk, just the operational one for an all-equity company, to which the same capital is subject because it's invested in a specific firm. Nevertheless, it remains, like the accounting net income, a partial measure of performance because it does not consider the component of the economic result related to the medium-long term perspective. Like any measure of residual income, $\mathrm{CVC}$ is therefore a measure potentially short sighted as exclusively focused on the present and, for this reason, not able to express the intensity and quality of efforts with whom company is fueling its competitive future. The removal of the above-mentioned reason for incompleteness leads to the determination of the second term needed to complete the economic result of the operational business activities: the strategic value creation SVC, investigated in the next section.

\section{a) Strategic value creation}

As above mentioned, the value creation is a comprehensive measure of all the economic benefits enjoyed, in a given period, by the holder of the capital invested and through this measure it's possible to evaluate the nature and quality of the competitive strategy. In this context, the strategic value creation SVC represents the portion of the economic result connected to the strategic governance of the business in a medium-long term perspective (as CVC incorporates the portion of the economic result actually realized in the current period). As the Goodwill is driven by expectations regarding future performance and the latter are the result of the strategic governance of the business, it follows that the CVS is reflected by the change, between two consecutive periods, of the Goodwill value. The CVS formula is the following:

$$
C V S=G_{1}-G_{0}
$$

where:

$\mathrm{G}_{1}=$ goodwill value at the time one

$\mathrm{G}_{0}=\quad$ goodwill value at the time zero

In relation to our numerical example, the strategic value creation is equal to 2.033 , that is the difference between the final, 4.891, and the beginning, 2.857, Goodwill values:

$$
\text { CVS }=4.891-2.857=2.033
$$

It's very interesting to note that the change in the goodwill value, led by its drivers, $\mathrm{E}, \mathrm{R}, \mathrm{t}_{\mathrm{c}}, \mathrm{CoE}, \mathrm{g}$ and CAP (please see the previous table 2), impacts on both $\mathrm{CVC}\left(\mathrm{Ni}-\mathrm{CoEx}\left(\mathrm{E}_{\mathrm{V} 1}+\mathrm{E}_{\mathrm{V} 0}\right) / 2\right.$ and $\mathrm{CVS}(\Delta \mathrm{G})$ and how it is strategically and operationally, at the same time, useful and simple highlight the relationship between every single $\mathrm{G}$ driver and the changing of the current and strategic value creation. This sensitivity analysis is a good way to identify strategic priorities and to improve competitiveness and value creation.

\section{b) Integrated value creation}

The path followed up to now has allowed us to identify the two components of value creation, CVC and SVC, each missing something and together capable of creating a complete economic measure, the integrated value creation. On the one hand, the Integrated Value Creation records, in terms relatively objective but fatally short-sighted, the events actually occurred during the year (revenues, costs, investments, etc.), and, on the other side, synthesizes, in a medium-long term perspective fatally more elusive of objective evaluations, expectations of future results.

The IVC formula is the following:

$$
I V C=C V C+S V C
$$

And, as concern the all-equity Alfa company:

$$
I V C=237+2.033=2.270
$$

In particular, the IVC: 
a. identifies a performance measure that mixes the two time references of the economic activity of the enterprise: the short-term, namely the administrative exercise, that is the present, and the medium-long term, ie the time horizon that goes beyond the next year, that is the future;

b. highlights the quality of the managerial work in moving deftly between two professional duties in potential contrast: on the one hand, the need to achieve results that will enable the company to operate autonomously in conditions of economic and financial equilibrium and, on the other side, the competitive duty to make decisions and employ resources in the present in order to promote the temporal duration of such conditions of independence and value creation;

c. is a true economic complete measure because includes a fair return on capital as a function of the company risk. In fact, a correct measurement result requires that the capital owned by the shareholders, expressed at the appropriate current value, is congruously remunerated in relation to the volatility of the expected economic results of the company;

d. allows, thanks to its focus on the competitive/business risk and duration of competitive advantage, to complete the overall view of all the ingredients necessary to fully assessing company strategies;

e. allows to measure the true economic performance of the shareholder (ESR, economic shareholder return) appreciating, in particular, the strategic $\left(\mathrm{ESR}_{\mathrm{S}}\right)$ and the current $\left(\mathrm{ESR}_{\mathrm{C}}\right)$ contributions. The ESR ratio is given by the relationship between IVC and the economic value of shareholders' equity $\left(V_{E}=E+G\right)$, appropriately averaged, and it is equal, in our numeric example, to $17,33 \%$ :

$$
E S R=I V C / V_{E}=2.270 /[(11.857+14.341) / 2]=17,33 \%
$$

In the same way $\mathrm{ESR}_{\mathrm{S}}$ and $\mathrm{ESR}_{\mathrm{C}}$ are respectively equal to the following values:

$$
\begin{gathered}
E S R_{S}=S V C / V_{E}=2.033 /[(11.857+14.341) / 2]=15,52 \% \\
E S R_{C}=C V C / V_{E}=237 /[(11.857+14.341) / 2]=1,81 \%
\end{gathered}
$$

The relationship between the above strategic and current shareholders returns, identifiable with the strategic consistency index SCI, highlights, on the one hand, the ability to govern the prospects of future profitability and, secondly, the balance between this attitude and the need to achieve a satisfactory level of profitability even in the present. The greater the ratio between $\mathrm{ESR}_{\mathrm{S}}$ and $\mathrm{ESR}_{\mathrm{C}}$ the more intense is the attention to the value of the goodwill compared to economic result achieved in the present. As concerns the Alfa company it's clear a prevalence of a long-vision strategy:

$$
S C I=E S R_{S} / E S R_{C}=15,52 \% / 1,81
$$

\section{The Framework of the Mapping of the Strategic Positioning and Sequencing}

Strategy maps are a valuable tool for strategic positioning and originate from the different crossing, thanks to the values assigned to them, of two (or more) variables properly selected with the aim of assessing the quality of business performance. Generally, as in this article, the strategy maps, based on the matrix approach, use a simple two-dimensional Cartesian system defined by an ordered pair of perpendicular lines (where the x-axis, the so-called abscissa, is taken to be horizontal and the y-axis, the so-called ordinate, is taken to be vertical), a single unit of length for both axes and an orientation for each axis. The axes of a two-dimensional Cartesian system divide the plane into four infinite regions, called quadrants, each bounded by two half-axes. These are often numbered from 1st to 4th and denoted by Roman numerals: I (where the signs of the two coordinates are I $(+,+)$, II $(-,+)$, III $(-,-)$, and IV $(+,-)$ (in according to the mathematical custom, the numbering goes counter-clockwise starting from the upper right -"northeast"- quadrant).

The strategic mapping want to provide, through a simple graphical representation of immediate understanding, a "snapshot" of the current strategic positioning of the company (the so-called "as is") to allow management to quickly interiorize the strategic priorities to be pursued, the more coherent resources, the pitfalls to be avoided, the fastest route and / or less risky (the so-called "to do") to get to the strategic position that the company wants to achieve (the so-called "to be"). When the analysis of strategic positioning is conducted for several periods the result is a strategic sequence, i.e. not just a snapshot but a path through several periods related to the evolution of the performance achieved by the company: this multi-period sequencing of the strategic positioning is an analysis consistent with the multi-year breath of the strategy and allows you to make an interesting quality assessment of the strategy itself.

In this paper will be examined two Strategic Guidance Maps (among the most known and used, the Product/Market Matrix of Ansoff, 1957, the Growth-Share Matrix of Boston Consulting Group, 1970, the Business Portfolio Matrix of McKinsey-General Electric, 1970, the Generic Strategies Matrix of Porter, 1980) both based on the integrated value creation model: 
1) the Strategic Positioning Map is focused to identify, in a given year, the strategic positioning of the company;

2) the Strategic Sequencing Map is focused to show the change over time of the above strategic positioning of the company.

As regards the Strategic Positioning Map (Figure 1), the following is noted:

a. there are two axes variables, expressed as a percentage of the periodic value production:

a1. the current value creation on the ordinate as the economic measure of the ability of the company to collect actual results in the present;

a2. the strategic value creation on the abscissa as the economic measure of the attitude of the company to prepare, well working in the present, its own competitive future;

b. on the starting assumption that the best company is the one who knows how to collect results in the present and at the same time it is able to sow/invest for the future, it's possible to identify the following four quadrants (Figure 1):

b1. in the 1st quadrant there are the "forward looking companies" with a long vision projected into the future and, in the same time, able to collect economic results in the present: this is the best strategic position and it shows a lasting value creation attitude;

b2. the 2nd quadrant represents companies who know how to create value in the short term but destroy value at the strategic level: if this position is a passage before coming back to the foresight then it is a temporary state of relaxation, while on the contrary if the company persists for several years in this quadrant then the judgment is the myopia and the risk of slipping, as a result of a exploitation strategy, in the criticality of the IV quadrant can be very high;

b3. in the 3rd quadrant there are the "blind companies" unable, at the same time, to invest into the future and to collect results in the present: the most significant risk for these companies is to be sucked in a process of negative screwing (a negative harvest leads to a poor sowing and which in turn leads to a poor harvest and so on); this is the worst strategic position and it shows a systematic value destruction attitude;

b4. in the 4th quadrant the companies are not able to create value in the present (probably the result of a not effective and profitable sowing in the past or a start-up activity or the application of a new business model) but they create strategic value focusing on the medium-long term: these companies are aware that coming back to create value implies the need to work for the future through a change strategy approach (based, for example, on product/process/customers/competences/strategic/etc innovation). Generally this quadrant, as well as that of relaxation, constitutes a phase of transition: companies can't afford to relax for a long time (otherwise the price is the entry in the criticality quadrant with its systematic destruction of value) or to constantly change their strategies / business models (the price to pay is the financial strain caused by the new investment needed to support the ever-changing and by the lack of the self financing).

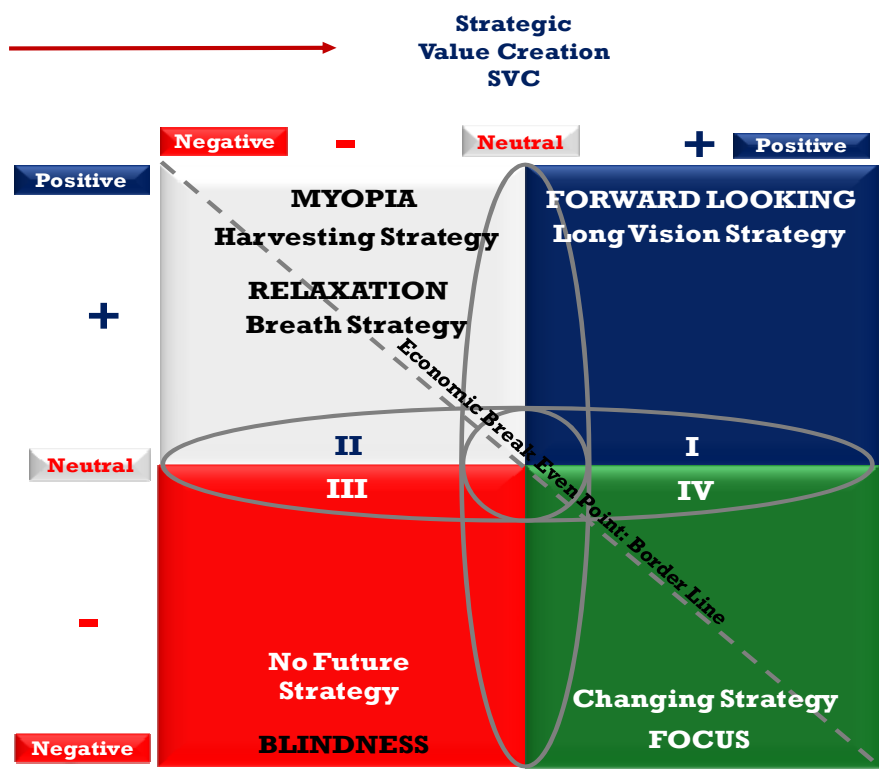

Figure 1. The strategic positioning map: a four quadrants matrix for (at least) four strategies 
c. the economic performance in terms of IVC is much better (worse) as the intersection between CVC and SVC is positioned away from the center of the matrix in the first (third) quadrant;

d. the bisecting line that cuts diagonally across the matrix through the second and fourth quadrant represents the border line of the economic break-even point $(\mathrm{IVC}=0)$ : to the right of the above bisecting line the integrated value creation is positive thanks to CVS $>\mathrm{CVC}$ and on the contrary to its left;

e. as more the companies are positioned near the origin of the axes and inside the circle in dark gray, the greater is the probability they will change the dial (a positive change if they operate effectively and efficiently, a negative change if they don't change their approach strategic), toward a better quadrant if the competitors are inertial / weak and on the contrary if the competitors are proactive / strong;

f. as more enterprises are positioned inside horizontal ellipse (always in dark gray), the greater the strategic component of value creation to be affected, positively or negatively, by the choices of the company;

g. as more enterprises are included within the vertical ellipse, the greater is the CVC and, therefore, is the short term to constitute the focus of choices of the company;

h. analyzing a multi-year horizon (see the following Strategic Sequencing Map) it's particularly useful to investigate the temporal sequence of the four quadrants strategic: from which quadrant started the company? and to continue toward which quadrant? and by what path? The different succession over time of the strategic quadrants is a valuable index of the strategic will/capability of an enterprise (and of the whole sector to which the company belongs).

As concerns the Strategic Sequencing Map:

1) the latter analyzes a multi-year horizon and it shows the over time path of the company between the different strategic positioning quadrants (please see the fig.2 for an example): the succession of the above different strategic quadrants is a valuable index of the strategic will/capability of an enterprise (and, in a broader perspective, of the whole sector);

\begin{tabular}{|c|c|c|c|c|}
\hline \multicolumn{5}{|c|}{ Strategic Sequences for the 2008 / 2011 Time Horizon - An Example } \\
\hline Sequences & 2008 & 2009 & 2010 & 2011 \\
\hline 1 & Forward Looking & Forward Looking & Forward Looking & Forward Looking \\
\hline 2 & Forward Looking & Relaxation & Forward Looking & Forward Looking \\
\hline 3 & Focus & Focus & Forward Looking & Forward Looking \\
\hline 4 & Blindness & Forward Looking & Forward Looking & Blindness \\
\hline
\end{tabular}

Figure 2. A strategic sequencing map example: from sequences to company's strategies

2) the choice of the duration of the time period analyzed determines the number of possible sequences: in a four-year Strategic Sequencing Map, for example, there are 256 theoretical combinations although those used are generally a significantly lower number;

3 ) in relation to each strategic sequence it's possible to associate a specific type of strategy and consequently a specific type of company. In particular, it's possible to identify eleven company profiles (Figure 3):

a. extra leading companies that, for the entire period, persist in the farsightedness quadrant confirming the ability to collect in the present $(\mathrm{CVC}>0)$ and to sow for the future (CVS $>0)$;

b. leading companies that realize three years of foresight on four and just one period of relaxation: these are companies that know how systematically create economic value;

c. excellent (good) companies that mix two years of foresight with two years of relaxation (if the years of relaxation are the last two the evaluation is transformed from excellent to good);

d. learning companies that gradually improve their strategic position from blindness to foresight through a focus, or changing strategy, phase;

e. diagonal companies that fluctuate between opposite quadrants of vision/blindness and relaxation/focus;

f. turnaround companies that change their strategic position almost every year;

g. down turnaround companies that change their strategic position with a tendency to the blindness; 
h. better late than never companies that, after years of blindness, are finally aware of the need to change strategy to avoid the bankruptcy;

i. confused companies that alternate criticality and relaxation failing to focus on a strategy for the future;

j. frog boiled companies that persist relaxed too long and risk of slipping into the blindness;

k. critical companies that, for the entire period, fail to escape the quadrant of blindness confirming to destroy value in the present $(\mathrm{CVC}<0)$ and for the future $(\mathrm{CVS}<0)$.

As concerns the above eleven company profiles it's very interesting to investigate the relationships between CVC and CVS in order to understand:

a. how many and which forward-thinking companies have been able to preserve this condition or, and after how long, have preferred to relax or are precipitated, and for which events, directly into the blindness quadrant or have opted, despite the high level of competitiveness, for a strategic change;

b. how many and which companies in a "blindness" condition have been able to regain the CVC (thus gaining precious energy to reinvest later for the future) or have opted, entering the focus quadrant, for a change strategy or have directly gained the foresight;

c. how many and which companies, from a previous phase of focus, have been able to achieve a winning changing strategy and conquered the foresight or, vice versa, have been sucked in by the "blindness" or are landed only to the current value creation;

d. how many and which companies from a strategy of exploitation have been able to escape to relax and regain the "foresight" or vice versa have consumed their competitive advantage by slipping into the "blindness" or have decided to change their strategies.

\begin{tabular}{|l|c|l|l|l|l|}
\hline \multicolumn{5}{|c|}{ Strategic Sequencing of the XY Economic Sector for the 2008 / 2011 Period } \\
and Company's Profiles \\
\hline \multicolumn{1}{|c|}{ Company's Profiles } & $\begin{array}{c}\text { Sequences } \\
\text { Number }\end{array}$ & \multicolumn{2}{|c|}{2008} & 2009 & 2010 \\
\hline Extra Leader companies & 1 & Forward Looking & Forward Looking & Forward Looking & Forward Looking \\
\hline Leader companies & 2 & Forward Looking & Relaxation & Forward Looking & Forward Looking \\
\hline Excellent (Good) companies & 3 & Relaxation & Forward Looking & Relaxation & Forward Looking \\
\hline Learning companies & 4 & Blindness & Focus & Focus & Forward Looking \\
\hline Diagonal companies & 5 & Blindness & Forward Looking & Forward Looking & Blindness \\
\hline Turnaround companies & 6 & Forward Looking & Relaxation & Blindness & Forward Looking \\
\hline Down Turnaround companies & 7 & Blindness & Focus & Forward Looking & Blindness \\
\hline Better late than never companies & 8 & Blindness & Blindness & Focus & Focus \\
\hline Confused companies & 9 & Focus & Blindness & Focus & Blindness \\
\hline Frog boiled companies & 10 & Forward Looking & Relaxation & Relaxation & Relaxation (Myopia) \\
\hline Critical companies & 11 & Blindness & Blindness & Blindness & Blindness \\
\hline
\end{tabular}

Figure 3. The strategic sequencing map: from 256 theoretical sequences to eleven strategies/company's profiles

In summary the Strategic Sequencing Map allows us to understanding in depth the quality of the strategic path of the company: the integrated value creation model, taking the size of risk and time, shows the ability of the company to balance the attention to collect results in the present with the need to build its own competitive future.

In this direction, the integrated value creation model dissolves the misunderstanding that lies behind the persistent criticisms that are often advanced by those who see in the effort to create value a dangerous goal for the destiny of the company, as a generator of an orientation maddeningly focused on a short term result. Such a charge would be perfectly legitimate if the creation of value coincide with the first of the two addends, i.e. CVC. But give absolute privilege to the maximization of CVC can only have the effect of penalizing future results and depressing SVC. For this reason, from a logical point of views, we can say that the pushing to maximize CVC can only lead to destroy value, penalizing SVC to the point of making negative IVC. 
As will be seen through the case study presented in the next paragraph, the above maps reveal their application utility for at least three sets of objectives:

a. the analysis of the dynamics of the sector as a whole, allowing you to identify the firms distribution (in time and in progress) in the four strategic quadrants and the consequent state of health of the economic sector;

b. the self-diagnosis of a single enterprise with its understanding of the economic / financial (net operating income and net capital invested) and competitive (risk and duration of competitive advantage) reasons which determine the strategic quadrant of belonging and its path over time;

c. the competitive analysis of the company compared to its competitors and the determinants that qualify its competitive positioning.

4. Wholesale Spare Parts Distribution in the Italian Automotive Independent After Market: Mapping of the Strategic Positioning and Sequencing through the Integrated Value Creation in the 2008-2011 Period

Since 2009, the Research Centre "Competitive Risk and Enterprise Value" of the Polytechnic of Turin, whose mission is to develop models and metrics for measuring business performance, set up a Market Observatory focused on the Italian Automotive Independent Aftermarket (IAM), on which there are 3.500 Limited Companies between Component Manufacturers, Wholesale Spare Parts Distributors and Spare Parts Retailers.

The present papers shows the results of the mapping of the positioning and sequencing related to the segment of the Wholesale Spare Parts Distributors through the integrated value creation realized in the 2008-2011 period. In Particular, the analysis sample includes 168 companies (out of a total of 184, in relation to the availability and homogeneity of data for the entire time period under analysis), representing more than $98 \%$ of the value of total production (approximately 2,0 billion euro).

As concerns the IAM 168 Wholesale Spare Parts Distributors, the Strategic Positioning Map shows the following (Figure 4):

a. the two most populated strategic quadrants are those of "foresight" (down from 32\% in 2008 to 29\% in 2011) and the "blindness" (down from 35\% in 2008 to 34\% in 2011) and this distribution confirms the polarization, although a slight decrease, of the competitive environment;

b. a slight reduction of companies that opt for a "strategic change" (from $23 \%$ in 2008 to $21 \%$ of the sample in 2011): they are the Wholesale Spare Parts Distributors that, while failing or refusing to collect the results in the present, "sow" for the future and increase the value of goodwill of their enterprise;

c. the companies in "relaxation", i.e. that collect in the present without sowing for the future and without enhancing the value of goodwill, increase their number from 17 units in $2008(10 \%)$ to 28 units in 2011 $(17 \%)$.

\begin{tabular}{|c|c|c|c|c|c|c|c|c|}
\hline $\begin{array}{c}\text { Strategic Positioning Map } \\
\text { IAM Wholesale Spare Parts } \\
\text { Distributors 2008-2011 }\end{array}$ & \multicolumn{2}{|c|}{2008} & \multicolumn{2}{|c|}{2009} & \multicolumn{2}{|c|}{2010} & \multicolumn{2}{|c|}{2011} \\
\hline Forward Looking & 54 & $32 \%$ & 56 & $33 \%$ & 48 & $29 \%$ & 48 & $29 \%$ \\
\hline Focus & 39 & $23 \%$ & 26 & $15 \%$ & 24 & $14 \%$ & 35 & $21 \%$ \\
\hline Relaxation & 17 & $10 \%$ & 25 & $15 \%$ & 28 & $17 \%$ & 28 & $17 \%$ \\
\hline Blindness & 58 & $35 \%$ & 61 & $36 \%$ & 68 & $40 \%$ & 57 & $34 \%$ \\
\hline Totale & 168 & $100 \%$ & 168 & $100 \%$ & 168 & $100 \%$ & 168 & $100 \%$ \\
\hline
\end{tabular}

Figure 4. The strategic positioning map related to the IAM wholesale spare parts distributors in the 2008-2011 period In relation to the Strategic Sequencing Map, the figures 5 and 6 highlight the strategic paths followed by the firms in the 2008-2011 period, what were the most populated and eleven different company profiles. In particular, the 61 active combinations on a total of 256 possible shows as follows:

a. the first four sequences excluded the third, equal to the $16,07 \%$ of the sample ( 27 companies), are characterized by an almost exclusive presence of "blindness" (the so-called "critical companies" and the "better late than 
never companies" of the first sequence): these companies, equivalent to the $11,06 \%$ of the total turnover, are, in the same time, unable to collect in the present and to sow for the future because of unawareness of competitive weaknesses or inability to face and solve these latter: in both cases the result is a systematic destruction of economic wealth; in the same bad condition there are further thirteen critical companies (see the sequences number 19,20,21,22 and 38) whose incidence on the total turnover is equal to $4,19 \%$;

b. the constant pressure of business and the consequent impossibility to relax for too long is confirmed by the absence of the "relaxation" sequence for all four years of the 2008-2011 analyzed period;

c. just one company changes each year its own strategy $(0,05 \%$ of the total turnover); this strategic sequence is not sustainable for two reasons: the first is that it shows too much managerial confusion and the second is that it needs too many financial resources;

d. the sequences 6,60 and especially 36 (4,44\% of the total turnover) shows companies in "relaxation" for two years and more and the recurrence of such carelessness towards the future changes the strategic assessment to "myopia" as it forms the basis for a probable "blindness";

e. the $17,86 \%$ of the sample $(35,26 \%$ of the total turnover) is made of "forward looking" companies (the so-called "extra leader" or "leader" companies): the latter are perfectly able of achieving in the same unit of time current and strategic value creation, or, in other word, to live with satisfaction the present and prepare the future wisely;

f. the "excellent companies" that fluctuate between foresight and relaxation constitute the $15,48 \%$ of the sample $(12,75 \%$ of the total turnover): their secret is knowing how to switch between collection and investment with great equilibrium without risking to relax for too long;

g. 27 companies out of 168 (i.e. $16,07 \%$ of the sample and $11,63 \%$ of the total turnover) change continuously (at least three times during the period 2008-2011) their dial, highlighting in some cases a high strategic instability that leads to "blindness" of the 4th year (the so-called down turnaround companies) while some companies gain a positive landing to the foresight or focus;

h. the $17,26 \%$ of the sample $(17,06 \%$ of the total turnover) consists of "confused" firms that move exclusively between "blindness" and "strategic change": in other words they are aware of their inability to create value, both in the present and for the future, and then they change strategy but they choose the wrong one or they do not know how to achieve it and return to "blindness";

i. further four companies (the so-called frog boiled companies, $4,38 \%$ of the total turnover) stagnate in a deep strategic lethargy due to excessive relaxation and risk to slip into the "blindness". 
Strategic Positioning of the IAM Wholesale Spare Parts Distributors and related Sequences for the 2008/2011 Period

\begin{tabular}{|c|c|c|c|c|c|c|c|c|}
\hline Company's Profiles & $\begin{array}{c}\text { Sequences } \\
\text { Number }\end{array}$ & 2008 & 2009 & 2010 & 2011 & $\begin{array}{c}\text { Companies } \\
\text { Number }\end{array}$ & $\begin{array}{l}\% \text { on the } \\
\text { Sample }\end{array}$ & $\begin{array}{l}\% \text { on the Total } \\
\text { Turnover }\end{array}$ \\
\hline Better late than never Companies & 1 & Blindness & Blindness & Blindness & Focus & 11 & $6,55 \%$ & $4,75 \%$ \\
\hline Critical Companies & 2 & Blindness & Blindness & Blindness & Blindness & 10 & $5,95 \%$ & $2,79 \%$ \\
\hline Extra Leader Companies & 3 & Forward Looking & Forward Looking & Forward Looking & Forward Looking & 7 & $4,17 \%$ & $3,02 \%$ \\
\hline Critical Companies & 4 & Focus & Blindness & Blindness & Blindness & 6 & $3,57 \%$ & $3,51 \%$ \\
\hline Better late than never Companies & 5 & Blindness & Blindness & Focus & Focus & 6 & $3,57 \%$ & $1,85 \%$ \\
\hline Excellent (Good) Companies & 6 & Forward Looking & Forward Looking & Relaxation & Relaxation (Myopia) & 6 & $3,57 \%$ & $3,31 \%$ \\
\hline Leader Companies & 7 & Forward Looking & Forward Looking & Relaxation & Forward Looking & 6 & $3,57 \%$ & $2,34 \%$ \\
\hline Leader Companies & 8 & Forward Looking & Relaxation & Forward Looking & Forward Looking & 5 & $2,98 \%$ & $2,52 \%$ \\
\hline Confused Companies & 9 & Focus & Blindness & Focus & Blindness & 5 & $2,98 \%$ & $4,30 \%$ \\
\hline Leader Companies & 10 & Forward Looking & Forward Looking & Forward Looking & Relaxation & 5 & $2,98 \%$ & $1,75 \%$ \\
\hline Down Turnaround Companies & 11 & Blindness & Focus & Forward Looking & Blindness & 4 & $2,38 \%$ & $1,92 \%$ \\
\hline Confused Companies & 12 & Blindness & Focus & Focus & Blindness & 4 & $2,38 \%$ & $1,80 \%$ \\
\hline Excellent Companies & 13 & Relaxation & Forward Looking & Relaxation & Forward Looking & 4 & $2,38 \%$ & $2,50 \%$ \\
\hline Confused Companies & 14 & Focus & Blindness & Blindness & Focus & 4 & $2,38 \%$ & $2,07 \%$ \\
\hline Confused Companies & 15 & Blindness & Focus & Blindness & Focus & 4 & $2,38 \%$ & $2,38 \%$ \\
\hline Confused Companies & 16 & Focus & Focus & Blindness & Focus & 4 & $2,38 \%$ & $3,68 \%$ \\
\hline Excellent Companies & 17 & Blindness & Forward Looking & Forward Looking & Relaxation & 4 & $2,38 \%$ & $2,39 \%$ \\
\hline Excellent Companies & 18 & Forward Looking & Relaxation & Forward Looking & Relaxation & 4 & $2,38 \%$ & $1,15 \%$ \\
\hline Critical Companies & 19 & Forward Looking & Blindness & Blindness & Blindness & 3 & $1,79 \%$ & $0,63 \%$ \\
\hline Critical Companies & 20 & Blindness & Forward Looking & Blindness & Blindness & 3 & $1,79 \%$ & $0,99 \%$ \\
\hline Critical Companies & 21 & Relaxation & Relaxation (Myopia) & Blindness & Blindness & 3 & $1,79 \%$ & $1,23 \%$ \\
\hline Critical Companies & 22 & Blindness & Blindness & Focus & Blindness & 3 & $1,79 \%$ & $1,17 \%$ \\
\hline Turnaround Companies & 23 & Forward Looking & Relaxation & Blindness & Forward Looking & 3 & $1,79 \%$ & $0,96 \%$ \\
\hline Leader Companies & 24 & Focus & Forward Looking & Forward Looking & Forward Looking & 3 & $1,79 \%$ & $23,79 \%$ \\
\hline Excellent Companies & 25 & Forward Looking & Relaxation & Relaxation (Myopia) & Forward Looking & 3 & $1,79 \%$ & $0,61 \%$ \\
\hline Leader Companies & 26 & Blindness & Forward Looking & Forward Looking & Forward Looking & 2 & $1,19 \%$ & $0,80 \%$ \\
\hline Confused Companies & 27 & Focus & Focus & Blindness & Blindness & 2 & $1,19 \%$ & $0,80 \%$ \\
\hline Diagonal Companies & 28 & Blindness & Forward Looking & Forward Looking & Blindness & 2 & $1,19 \%$ & $1,09 \%$ \\
\hline Confused Companies & 29 & Focus & Focus & Focus & Blindness & 2 & $1,19 \%$ & $0,18 \%$ \\
\hline Down Turnaround Companies & 30 & Relaxation & Forward Looking & Relaxation & Blindness & 2 & $1,19 \%$ & $0,82 \%$ \\
\hline Diagonal Companies & 31 & Forward Looking & Blindness & Blindness & Forward Looking & 2 & $1,19 \%$ & $0,47 \%$ \\
\hline Leader Companies & 32 & Relaxation & Forward Looking & Forward Looking & Forward Looking & 2 & $1,19 \%$ & $1,03 \%$ \\
\hline Excellent Companies & 33 & Focus & Forward Looking & Relaxation & Forward Looking & 2 & $1,19 \%$ & $1,12 \%$ \\
\hline Turnaround Companies & 34 & Forward Looking & Blindness & Blindness & Focus & 2 & $1,19 \%$ & $0,64 \%$ \\
\hline Frog Boiled Companies & 35 & Relaxation & Relaxation (Myopia) & Forward Looking & Relaxation & 2 & $1,19 \%$ & $3,77 \%$ \\
\hline Frog Boiled Companies & 36 & Forward Looking & Relaxation & Relaxation (Myopia) & Relaxation (Myopia) & 2 & $1,19 \%$ & $0,60 \%$ \\
\hline Turnaround Companies & 37 & Focus & Blindness & Blindness & Forward Looking & 2 & $1,19 \%$ & $1,13 \%$ \\
\hline Critical Companies & 38 & Relaxation & Blindness & Blindness & Blindness & 1 & $0,60 \%$ & $0,17 \%$ \\
\hline Down Turnaround Companies & 39 & Focus & Forward Looking & Blindness & Blindness & 1 & $0,60 \%$ & $0,82 \%$ \\
\hline Down Turnaround Companies & 40 & Forward Looking & Relaxation & Blindness & Blindness & 1 & $0,60 \%$ & $0,12 \%$ \\
\hline Diagonal Companies & 41 & Forward Looking & Blindness & Forward Looking & Blindness & 1 & $0,60 \%$ & $0,20 \%$ \\
\hline Down Turnaround Companies & 42 & Focus & Focus & Forward Looking & Blindness & 1 & $0,60 \%$ & $0,28 \%$ \\
\hline Down Turnaround Companies & 43 & Forward Looking & Blindness & Focus & Blindness & 1 & $0,60 \%$ & $0,08 \%$ \\
\hline Down Turnaround Companies & 44 & Blindness & Forward Looking & Relaxation & Blindness & 1 & $0,60 \%$ & $0,11 \%$ \\
\hline Down Turnaround Companies & 45 & Forward Looking & Relaxation & Relaxation (Myopia) & Blindness & 1 & $0,60 \%$ & $0,15 \%$ \\
\hline Diagonal Companies & 46 & Blindness & Forward Looking & Blindness & Forward Looking & 1 & $0,60 \%$ & $0,03 \%$ \\
\hline Turnaround Companies & 47 & Focus & Forward Looking & Blindness & Forward Looking & 1 & $0,60 \%$ & $0,12 \%$ \\
\hline Turnaround Companies & 48 & Blindness & Focus & Blindness & Forward Looking & 1 & $0,60 \%$ & $0,26 \%$ \\
\hline Turnaround Companies & 49 & Focus & Blindness & Forward Looking & Forward Looking & 1 & $0,60 \%$ & $0,60 \%$ \\
\hline Excellent Companies & 50 & Focus & Focus & Forward Looking & Forward Looking & 1 & $0,60 \%$ & $0,43 \%$ \\
\hline Turnaround Companies & 51 & Focus & Blindness & Focus & Forward Looking & 1 & $0,60 \%$ & $2,46 \%$ \\
\hline Confused Companies & 52 & Forward Looking & Forward Looking & Blindness & Focus & 1 & $0,60 \%$ & $0,21 \%$ \\
\hline Confused Companies & 53 & Forward Looking & Relaxation & Blindness & Focus & 1 & $0,60 \%$ & $1,35 \%$ \\
\hline Confused Companies & 54 & Blindness & Focus & Focus & Focus & 1 & $0,60 \%$ & $0,21 \%$ \\
\hline Confused Companies & 55 & Focus & Focus & Focus & Focus & 1 & $0,60 \%$ & $0,06 \%$ \\
\hline Turnaround Companies & 56 & Relaxation & Blindness & Forward Looking & Relaxation & 1 & $0,60 \%$ & $0,18 \%$ \\
\hline Excellent Companies & 57 & Focus & Forward Looking & Forward Looking & Relaxation & 1 & $0,60 \%$ & $0,25 \%$ \\
\hline Excellent Companies & 58 & Relaxation & Forward Looking & Forward Looking & Relaxation & 1 & $0,60 \%$ & $1,00 \%$ \\
\hline Turnaround Companies & 59 & Focus & Focus & Forward Looking & Relaxation & 1 & $0,60 \%$ & $0,25 \%$ \\
\hline Down Turnaround Companies & 60 & Blindness & Forward Looking & Relaxation & Relaxation (Myopia) & 1 & $0,60 \%$ & $0,52 \%$ \\
\hline \multirow[t]{2}{*}{ Turnaround Companies } & \begin{tabular}{|r|}
61 \\
\end{tabular} & Relaxation & Blindness & Blindness & Forward Looking & 1 & $0,60 \%$ & $0,26 \%$ \\
\hline & \multicolumn{5}{|c|}{61 active combinations on a total of 256} & 168 & $100,00 \%$ & $100,00 \%$ \\
\hline
\end{tabular}

Figure 5. The strategic sequencing map related to the IAM wholesale spare parts distributors in the 2008-2011 period 


\begin{tabular}{|l|c|c|c|c|}
\hline \multicolumn{1}{|c|}{ Company's Profiles } & $\begin{array}{c}\text { Sequences } \\
\text { Number }\end{array}$ & 2008-2011 & \% on the Sample & $\begin{array}{c}\text { \% on the Total } \\
\text { Turnover }\end{array}$ \\
\hline Extra Leader companies & 1 & 7 & $4 \%$ & $3 \%$ \\
\hline Leader companies & 2 & 23 & $14 \%$ & $32 \%$ \\
\hline Excellent (Good) companies & 3 & 26 & $15 \%$ & $13 \%$ \\
\hline Learning companies & 4 & 0 & $0 \%$ & $0 \%$ \\
\hline Diagonal companies & 5 & 6 & $4 \%$ & $2 \%$ \\
\hline Turnaround companies & 6 & 13 & $8 \%$ & $7 \%$ \\
\hline Down Turnaround companies & 7 & 14 & $8 \%$ & $5 \%$ \\
\hline Better late than never companies & 8 & 17 & $10 \%$ & $7 \%$ \\
\hline Confused companies & 9 & 29 & $17 \%$ & $17 \%$ \\
\hline Frog boiled companies & 10 & 4 & $2 \%$ & $4 \%$ \\
\hline Critical companies & 11 & 29 & $17 \%$ & $10 \%$ \\
\hline Total & & 168 & $100 \%$ & $100 \%$ \\
\hline
\end{tabular}

Figure 6. From the strategic sequencing map to the company's profiles as concerns the IAM wholesale spare parts distributors in the 2008-2011 period

\section{Concluding Remarks}

The integrated value creation (IVC) model and the mapping strategic positioning and sequencing (MSPS) are presented to management judgment with two precious leading points: a high degree of completeness and mutual integrability. The IVC is a comprehensive measure capable of synthesizing in a single parameter, including two key issues such as the opportunity cost of capital and the duration of the competitive advantage, the results realized in the present, the so called CVC, and the portion of the economic result resulting from the improvement in the outlook of future results, the so-called SVC. The strategic positioning and sequencing maps constitute a complete representation of the strategic choices made by the company because, by mixing the time perspective of short-term to long-term, they give full evidence, consistent with the breath of multi-year strategy, of the true quality of a corporate strategy, that is the ability to generate long-lasting results. Both IVC and MSPS are also highly integrated as if it's true that, on the one hand, the goal of business strategies is to create value with continuity, it's equally true that, on the other side, the quality, quantity and duration of creating value are the true mirror of the strategic choices of the company.

If it is true that the evaluation of business is littered with traps, illusions, false beliefs, assumptions, then the more it is necessary that the measures of the competitive quality of the enterprise, in the dual economic and strategic perspective, are not confused by positive results but by the fleeting breath, or groped by comfortable and without sacrifice results, and self-protect by short-sighted results, but on the contrary give full evidence of the strategic ability of the company to settle the need to "pick up" in the present to the vital need of "sow seeds" for the future.

In this direction the model of Integrated Value Creation and the maps related to the strategic positioning and sequencing of the enterprise, of which it is given an example of a possible integrated use, constitute a certainly useful reference (and just as certainly perfectible) to force the enterprise system, and in particular the management who leads it, to appreciate clearly the fruits of the present and those of the future as a direct consequence of the strategy and to work for the continuous improvement of both.

\section{References}

Ansoff, I. (1957, Sep-Oct.). Strategies for Diversification. Harvard Business Review, 35(5), 113-124.

Bennet Stewart G. III. (2013). The quest for value. Harper Collins, New York.

Besanko D., Dranove D., \& Shanley M. (2000). Economics of Strategy. Wiley, NY.

Costantini P. (2006). Cash return on capital invested. Butterworth-Heinemann, Oxford.

Damodaran A. (2004). Investment Valuation. Wiley, NY.

Donna G. (2003). L'impresa multibusiness. Università Bocconi Editore, Milano.

Fama, Eugene F., \& French, Kenneth R. (1997). Industry costs of equity. Journal of Financial Economics, 43(2), 158-193. http://dx.doi.org/10.1016/S0304-405X(96)00896-3

Francis, Jennifer et al. (2004). Costs of Equity and Earnings Attributes. The Accounting Review, 79(4), 967-1010. http://dx.doi.org/10.2308/accr.2004.79.4.967 
Greenwald B., Kahn J., Sonkin P., \& Van Biema M. (2004). Value Investing. Wiley, NY.

Lintner J. (1965, February). The Valuation of Risk Assets and the Selection of Risky Investments in Stock Portfolios and Capital Budgets. Review of Economics and Statistics, 47, 13-37. http://dx.doi.org/10.2307/1924119

Marshall A. (1920). Principles of Economics. McMillan and Co., London.

Mauboussin M., \& Johnson P. (1997). Competitive Advantage Period. The Neglected Value Driver. Financial Management Association, 26, summer. http://dx.doi.org/doi 10.2307/3666168

Miller M. (1977). Debt and taxes. Journal of finance, 32, 261-275. http://dx.doi.org/10.1111/j.1540-6261.1977.tb03267

Modigliani F., \& Miller M. (1958). The cost of capital, corporation finance and the theory of investment. American Economic Review, 48, 261-297.

Modigliani F., \& Miller M. (1963). Corporation income taxes and the cost of capital: A correction. American Economic Review, 53, 433-443.

Myers S. (1974, March). Interactions of Corporate Financing and Investment Decisions - Implications for Capital Budgeting. Journal of Finance, 1-25. http://dx.doi.org/10.2307/2978211

Porter, M.E. (1979, March-April). Competitive Strategy: Techniques for analyzing industries and competitors. New York, The Free Press.

Porter, Michael. (1987, May-June). From Competitive Advantage to Corporate Strategy. Harvard Business Review, (3), 43-59.

Prahalad, C.K., \& Hamel, G. (1990). The core competence of the corporation. Harvard Business Review, 68(3), 79-91. http://dx.doi.org/10.1016/B978-0-7506-7088-3.50006-1

Rappaport A. (1998). Creating Shareholder Value. The New Standard for Business Performance. New York, The Free Press.

Rappaport A., \& Mauboussin M. (2001). Expectations Investing. Harvard Business School Press.

Sharpe W.F. (1964, September). Capital Asset Prices: A Theory of Market Equilibrium under Conditions of Risk. Journal of Finance, 19, 425-442. http://dx.doi.org/10.2307/2977928

Treynor, Jack L. (1961). Market Value, Time, and Risk. Unpublished manuscript dated 8/8/61, No. 95-209. 